\title{
A IDENTIDADE COLECTIVA EN GALICIA NO ESPELLO BRETÓN (SÉCULOS XIX E XX): UNHA INTERPRETACIÓN
}

\author{
Xosé M. Núñez Seixas
}

Universidade de Santiago de Compostela Consello da Cultura Galega

DOI: $10.17075 / g b o c .2020 .008$ 

Neste texto levaremos a cabo un breve percorrido histórico de longa duración pola identidade colectiva na Idade Contemporánea dos galegos e das galegas. Non se abordará unha prospección sociolóxica ou baseada en inquéritos recentes, aínda que tamén se recorrerá a estudos fundamentados neste tipo de metodoloxías. Tomaremos como punto de comparanza e referencia obrigada o caso doutra fisterra europea, a Bretaña, sen pretendermos levar a cabo unha análise plenamente comparativa, xa que outros artigos neste mesmo volume tratan con maior profundidade e coñecemento o caso bretón. Tentaremos desenvolver un ensaio de historia transnacional, ma non troppo, no que a Bretaña desempeña o papel de espello alternativo, ben como de expoñente da maneira en que dous territorios periféricos, dotados de forte personalidade colectiva, histórica e cultural, poden experimentar dinámicas diverxentes ao longo dos séculos XIX e XX. E iso, en boa medida, débese ao feito de atopárense incluídos en dous Estados nacionais con dinámicas en moitos aspectos semellantes, mais noutros igualmente diverxentes, como son España e Francia.

Cómpre sinalar, de entrada, que o concepto de identidade colectiva é obxecto de permanente discusión nas ciencias sociais. En parte, polo seu carácter volátil, difícil de captar como realidade intersubxectiva, máis aínda ao tratarmos do pasado, cando non é posíbel recorrer ás ferramentas usuais empregadas polos sociólogos, como os inquéritos de opinión. En parte por esas eivas metodolóxicas, autores hai que mesmo negan a súa existencia como fenómeno perceptíbel ou rexistrábel para o observador externo ${ }^{1}$. Hai tamén quen considera máis operativo aludir a lealdades, isto é, a relacións afectivas que traducen escollas conscientes, mais tamén habitus herdados e relacións entre poderes, institucións ou persoas físicas e concretas ${ }^{2}$. Nalgúns casos pode resultar máis operativo referírmonos a identidades colectivas compartidas ou mixtas; noutros casos, a identidades híbridas, de fronteiras esluídas e mudábeis. Mais, en todo caso, son procesos dinámicos e cambiantes, que non han verse xamais como unha botella que se «enche», senón como un proceso relacional e dinámico, no cal os actores concretos, as persoas, tamén teñen algunha cousa que dicir. Iso tradúcese non só nunha oferta cultural, nunha mensaxe "dende enriba», senón tamén nunha resposta dende

1 Anthony P. Cohen (1996): «Personal nationalism: a Scottish view of some rites, rights, and wrongs», American Ethnologist, 23:4, 802-815.

2 Jana Osterkamp / Martin Schulze-Wessel (eds.) (2017): Exploring Loyalty, Göttingen, V\&R. 
abaixo, nunha retroalimentación entre a esfera individual, a pública e a semipública $^{3}$. Outros máis prefiren — preferimos — pór o acento na esfera persoal e na capacidade dos individuos para, dende abaixo, asociárense e sentírense solidarios cun colectivo. Daquela, gañan peso non tanto as identidades, concepto tendencialmente holístico, como os procesos de identificación, sublimando o carácter de adscrición persoal que toda identidade posúe. Por tanto, insístese dende esta perspectiva na necesidade de situarmos o foco na experiencia individual das persoas, no mundo das súas percepcións, preferencias e emocións, dende unha óptica que dá prioridade ao «nacionalismo persoal» da vida diaria. Unha sorte de «nacionalismo cotián» que constrúe a nación non só de enriba abaixo, como unha empresa impulsada polas institucións, asociacións e colectivos organizados, senón tamén dende abaixo, como un sistema de significados construídos en interacción coas escollas individuais e grupais ${ }^{4}$.

O espello bretón no que ollaremos a evolución da identidade colectiva de Galicia ten sido, polo demais, sumamente idealizado no seo da propia Galicia polo menos a partir da segunda década do século Xx. Foino dende unha perspectiva literaria, histórica e musical, tamén coa evocación saudosa dunha parentela ou común xinea "céltiga", complementaria á paralela fascinación sentida polos galeguistas e pola cultura galega en xeral por outra «nación céltiga», Irlanda, sorte de irmá maior xa emancipada e moito menos coñecida. A máis grande proximidade e familiaridade das elites culturais galeguistas co universo francés e francofalante resultou, nese senso, determinante, mentres que os mediadores culturais con Irlanda foron moito máis serodios e escasos ${ }^{5}$.

Porén, e fronte ao caso de Irlanda, existiu unha longa ringleira de contactos directos e indirectos que serven de fitos nos que apoiar a relación intelectual e algunhas transferencias culturais entre Galicia —ou, mellor dito, o galeguismo cultural - e a Bretaña como obxecto, e non tanto o movemento nacionalista ou

3 Alejandro Quiroga (2014): «The three spheres. A theoretical model of mass nationalisation: the case of Spain", Nations and Nationalism, 20:4, 683-700.

4 Andreas Stynen / Maarten Van Ginderachter / Xosé M. Núñez Seixas (2020): «Introduction: Emotions and Everyday Nationalism in Modern European History», en íd. (eds.), Emotions and Everyday Nationalism in Modern European History, London, Routledge, 1-15.

5 Nomeadamente, a figura de Plácido Castro, obxecto, polo demais, nos tempos recentes de grande idealización. Cf. Plácido R. Castro del Río (2011): Irlanda en Plácido Castro, Redondela, IGADI. 
cultural bretón, que tendeu a ignorar amplamente a existencia de Galicia até a década de 1960. Fitos daquela relación foron os contactos epistolares e intercambios entre a Xeración Nós e varios órganos bretonnants, do que son testemuño as páxinas da revista ourensá do mesmo nome dende a súa fundación no 1920, ben como o rol de mediador e tradutor desempeñado polo políglota ensaísta e editor do Mercure de France Philéas Lebesgue ${ }^{6}$, e mais a visita de Alfonso R. Castelao no ano 1928 en viaxe de estudos, froito do cal foi o seu álbum As cruces de pedra na Bretaña ${ }^{7}$. Na posguerra, esa tradición xa non se baseou tanto nas visitas e contactos directos como nas evocacións literarias dende a distancia, a recreación distópica de Galicia nunha Bretaña coñecida a través do espello da historia e das lendas artúricas. Testemuño diso foron obras como As crónicas do sochantre (1956), de Álvaro Cunqueiro, produto da súa fascinación pola Bretaña e mais por Chateaubriand asemade, e Bretaña, Esmeraldina (1987), de Xosé Luís Méndez Ferrín, escenario distópico da revolución nacional e social soñada polo autor e situada nunha Bretaña imaxinada. Todos eles eran exemplos da que sería unha vertente particular da «materia da Bretaña» ou ciclo artúrico na tradición literaria galega, que tamén abranguería autores como Carlos G. Reigosa e Eva Moreda ${ }^{8}$. Adoito, a Bretaña convertíase para estes e outros autores nun espello, nun obxecto de evocacións cuxa realidade se coñecía menos do que se invocaba e ao que se atribuían calidades ou características semellantes ás que se tiñan no propio país. De feito, até a década de 1970 os contactos políticos foron escasos ou case nulos, e só se relanzaron co gallo da preparación, por parte dos expoñentes dos novos nacionalismos de esquerda anticolonial na Bretaña, Galicia, Córsega e outras nacionalidades da Europa occidental, dun texto conxunto, a Carta de Brest, asinada naquela cidade bretoa no 1972, aínda que en realidade publicada no 1974 .

6 Antón Figueroa (1996): Lecturas alleas: sobre as relacións con outras literaturas, Santiago de Compostela, Sotelo Blanco.

7 Alfonso Rodríguez Castelao (1930): As cruces de pedra na Bretaña, Santiago de Compostela, Seminario de Estudos Galegos.

8 Cf. María Xesús Lama López (2002): O celtismo e a materia de Bretaña na literatura galega: cara á construción dun contradiscurso histórico ficcional na obra de Xosé Luis Méndez Ferrín, tese de doutoramento, Barcelona, Universitat de Barcelona.

9 Vid. para unha descrición exhaustiva por parte dun protagonista, exiliado en París durante un tempo e bo coñecedor do nacionalismo bretón na altura, Luís Gonçales Blasco «Foz» (2012): A política e a organizaçom exterior da UPG (1964-1986), Santiago de Compostela, Laiovento. 
Galicia e a Bretaña son dúas arquetípicas fisterras de occidente; se se quere, dúas periferias atlánticas europeas. Unha, Galicia ou Galiza, é un territorio tipicamente atlántico no recanto noroeste dunha península periférica dentro da Europa occidental, a Península Ibérica/España. Outra, a Bretaña (Breizh), é tamén unha periferia atlántica, nun recanto igualmente do noroeste, mais dun Estado-nación que durante moito tempo foi e segue a ser considerado o «centro» económico e político da Europa occidental, ben como do pensamento e da cultura, Francia/ París. Ambas as dúas rexións históricas posúen unha forte personalidade colectiva, que as fai comparábeis en moitos aspectos. Porén, o caso da Bretaña resultou ser moito máis rechamante cara ao exterior que a descoñecida Galicia, pois aquela desfruta dunha moito maior visibilidade como entidade recoñecíbel dentro de Francia, malia a maior debilidade relativa do seu propio rexionalismo/nacionalismo e a menor puxanza dos seus idiomas propios, o bretón e mais o galó, na contemporaneidade. Tamén por iso, a Bretaña foi e é moito máis merecente de atención, na bibliografía especializada internacional sobre as identidades territoriais, os rexionalismos e os nacionalismos, do que o foi Galicia até o de agora ${ }^{10}$.

Así e todo, e enxergadas dende o "centro» dos seus respectivos Estados-nación, tanto Galicia como a Bretaña compartiron, e aínda partillan, a característica de seren olladas cunha mestura de menosprezo e de fascinación asemade. $\mathrm{O}$ estigma do atraso e do carácter periférico, de constituíren territorios pobres e maioritariamente agrarios (ou agro-mariñeiros), acompañábase ademais da fascinación sentida dende París e Madrid, transmitida pola súa vez por viaxeiros, turistas e emigrados, por algúns dos seus trazos étnicos, polos seus supostos costumes ancestrais. Compartiron ambos os dous territorios así mesmo o estereotipo de

${ }^{10}$ Cf., por exemplo, Patricia Elton Mayo (1974): The Roots of Identity: Three National Movements in Contemporary Politics, London, Allen Lane; Caroline Ford (1993): Creating the Nation in Provincial France: Religion and Political Identity in Brittany, Princeton, NJ, Princeton University Press; Sharif Gemie (2007): Brittany 1750-1950: The Invisible Nation, Cardiff, University of Wales Press, ou Patrick Young (2012): Enacting Brittany: Tourism and Culture in Provincial France, 1871-1939, Farnham, Ashgate. Para o caso de Galicia, amais de artigos varios e de traducións de obras publicadas por autores galegos, só existen dúas monografías noutras linguas dignas de mención: Sharif Gemie (2006): A Concise History of Galicia, Cardiff, University of Wales Press, e a obra da profesora galega de estudos culturais Helena Miguélez-Carballeira (2013) Galicia, a Sentimental Nation: Gender, Culture and Politics, Cardiff, University of Wales Press, ben como íd. (ed.) (2014): A Companion to Galician culture, Woodbrige, Tamesis. 
seren terras tradicionais e refuxio da reacción fronte ao liberalismo e a modernidade, dende a guerra da Vendée e a resistencia dos chouans labregos contra da Revolución Francesa. Era, no caso da Bretaña, unha imaxe do século XIX, que tería eco con cada vez máis debilidade no novecentos. Pola contra, no caso galego tratouse dunha icona máis persistente durante o século xx, xa que o carlismo en Galicia -o equivalente dos lexitimistas e chouans — foi máis ben minoritario socialmente. Porén, a Galicia conservadora ergueuse como unha imaxe dominante do país dende a Guerra Civil española e, nomeadamente, dende o primeiro franquismo. Unha icona que foi delongada dende a Transición á democracia como unha sorte de Baviera española, bastión do conservadorismo e do medo á mudanza. Galicia sería un territorio que, coma a Bretaña, reaccionaría só de xeito asíncrono e con demora ás variacións dos ventos políticos no centro do Estado. E que, tamén coma a Bretaña, conxugaba misterio e crenzas ancestrais con atraso e ruralidade. Igualmente, ambas as dúas periferias serían exemplos de ambigüidade e paradoxo no que fai á cuestión nacional. Isto é, territorios onde, xa dende comezos de século (Bretaña) ou dende a década de 1930 (Galicia), habería algúns partidos ou grupos non só nacionalistas, senón mesmo arredistas; mais neses territorios naceron tamén ditadores e dirixentes reaccionarios e conservadores identificados co nacionalismo de Estado, fosen aqueles españois (José Calvo Sotelo, Francisco Franco, Manuel Fraga) ou franceses (Jean-Marie Le Pen).

Con todo, na era das nacións, dos nacionalismos dos Estados nacionais, tanto a Bretaña como Galicia son definíbeis como ethnies, no senso descrito por Anthony D. Smith ${ }^{11}$. Isto é, territorios cunha forte etnicidade diferencial (lingua, características de cultura material etc.), cuxos trazos diacríticos foron, en boa parte, preservados grazas ao seu illamento xeográfico ou ao seu relativo atraso económico —ou a ambos os dous_-, mais que posuían febles ou distantes referentes de autogoberno colectivo no pasado. Eses referentes estaban máis presentes no caso da Bretaña, onde o Ducado da Bretaña independente persistiu até 1532, cando foi incorporado ao Reino de Francia. Pola contra, o Reino de Galicia só de maneira esporádica chegou a conformar unha comunidade política propia, pois dende moi axiña foi incorporado á Coroa de León/Castela.

${ }^{11}$ Anthony D. Smith (1986): The Ethnic Origins of Nations, Oxford, Blackwell. 
Ambas as dúas fisterras europeas presentan, xa no tempo histórico dos nacionalismos (séculos XIX e XX), un trazo relativamente común: o hiperdesenvolvemento ideolóxico e mais a precoz diversificación da oferta política dos seus respectivos movementos de reivindicación rexionalista, e andando o tempo etnonacionalista. Ese movemento naceu denantes, e radicalizouse con máis rapidez, no caso bretón que no caso galego. E as súas formulacións teóricas foron seguidas só dun apoio social moi relativo, sen chegaren a coller folgos nin antes de 1914, nin no tempo de entre as guerras, nin tampouco no período da posguerra. $\mathrm{O}$ grao de apoio social ao etnonacionalismo na Bretaña foi sempre moito menor que en Galicia. A iso axudaban tamén un diferente contexto político-institucional e mais unha estrutura de oportunidade política máis desfavorábel no caso bretón, suxeito a un sistema electoral máis restritivo cara ás minorías políticas do que foi o imperante na Galicia da II República ${ }^{12}$.

A Bretaña, en todo caso, foi a primeira periferia «rebelde» de Francia, de xeito paralelo ao movemento occitanista do Félibrige, comezando polo seu temperán espertar cultural a finais da década de 1830, cando Théodore Hersart de la Villemarqué publicou a recompilación de cantos e narracións populares en bretón Barzaz Breiz. Foi, en todo caso, a partir daqueles dous focos, a Bretaña e o mediodía francés, dende onde o chamado movemento rexionalista colleu pulo no Hexágono todo, para dar lugar á fundación da Federación Rexionalista Francesa no 1900; non deixaba de ser un paradoxo máis do caso francés o feito de que existise unha organización rexionalista de carácter estatal. Emporiso, o certo foi que, dende os primeiros pasos da súa andaina, os rexionalistas franceses ían nunha dirección, a da rexionalización político-administrativa de enriba abaixo, mentres os bretóns empurraban noutra, moito máis vencellada ao que eran os ecos dos movementos nacionalistas de raigame romántica e culturalista e que asociaba a reivindicación política á etnicidade e mais á historia. Desta maneira, a primeira organización política bretonnante, a Unión Rexionalista da Bretaña (1898), dominada por grandes propietarios agrarios e aristócratas, deu lugar no 1911 a dous grupos, a Federación Rexionalista Bretoa, de selo liberal,

12 Para unha visión xeral do movemento bretón ou emsav, cf. Michel Nicolas (2007): Histoire de la revendication bretonne, Spézet, Coop Breizh. 
e o máis radical Partido Nacional Bretón, abertamente nacionalista, católico e partidario da independencia da Bretaña ${ }^{13}$.

O estalido da Primeira Guerra Mundial, que supuxo unha mobilización masiva de mozos bretóns para as frontes de combate e a súa practicamente definitiva nacionalización como franceses, tamén tivo consecuencias para o movemento bretón. Varios mozos excombatentes radicalizaron o seu sentimento identitario á volta das trincheiras, no 1918, e fundaron o semanario Breiz Atao ("A Bretaña sempre»), inzados de inconformismo xeracional, culto á patria e irracionalismo. Ao pouco tempo, o novo nacionalismo bretón esgazou entre unha tendencia federalista e mais outra nacionalista integral, que nos anos trinta adoptaría un rumbo profascista. Nesa altura, o movemento bretón ficou escurecido en parte pola meirande puxanza do movemento alsaciano entre 1926 e $1939^{14}$.

Así e todo, pódese afirmar que os nacionalistas e federalistas bretóns foron até o comezo da Segunda Guerra Mundial o «laboratorio de ideas» preferente dos nacionalismos subestatais da Francia toda. Fíxose evidente así na actividade do federalista e europeísta bretonnant Maurice Duhamel nos anos vinte, ben como na fundación do Comité central des minorités nationales de France no ano 1927 na cidade bretoa de Rosporden, a iniciativa precisamente do sector federalista do movemento bretón, que se constituíu naquel mesmo ano en Parti autonomiste breton (PAB). Velaí un dos xermolos do concepto da «Europa dos pobos», que se desenvolvería na posguerra como inspiración do artellamento continental dos novos nacionalismos subestatais da Europa occidental ${ }^{15}$.

13 Anne-Marie Thiesse (1992): «L'invention du régionalisme à la Belle Époque», Le Mouvement social, 160, 11-32; íd. (1991): Écrire la France : le mouvement littéraire régionaliste de langue française entre la Belle-Époque et la Libération, Paris, Presses universitaires de France; Julian Wright (2003): The Regionalist Movement in France: Jean Charles-Brun and French Political Thought, Oxford, Oxford University Press.

${ }^{14}$ Alain Déniel (1976): Le Mouvement breton, 1919-1945, Paris, Maspero; Francis Arzalier (1990): Les Perdants : la dérive fasciste des mouvements autonomistes et indépendantistes au XXe siècle, Paris, La Découverte; Sébastien Carney (2015): Breiz Atao! Mordrel, Delaporte, Lainé, Fouéré : une mystique nationale (1901-1948), Rennes, Presses Universitaires de Rennes, 189-220. Vid. tamén Xosé M. Núñez Seixas (2004): Movimientos nacionalistas en Europa: siglo XX, Madrid, Síntesis, 187-192 e 259-261, ben como o clásico Jean-Yves Guiomar (1970): «Régionalisme, fédéralisme et minorités nationales en France entre 1919 et 1939», Le Mouvement Social, 70, 89-108.

15 Maurice Duhamel (1978 [1929]): La question bretonne dans son cadre européen, Quimper/Kemper, Nature et Bretagne; máis detalles en Xosé M. Núñez Seixas (2019): Patriotas transnacionales: estudios sobre nacionalismos y transferencias culturales en la Europa del siglo XX, Madrid, Cátedra, 55-72. 
A colaboración cos ocupantes alemáns de boa parte dos nacionalistas bretóns entre 1940 e 1944, incluída a conformación dunha modesta milicia, deixou un estigma de deslexitimación sobre as reivindicacións bretonnantes. Esa mácula estenderíase até finais da década de 1950, cando comezou unha reformulación en clave esquerdista do legado nacionalista bretón, á luz de novas influencias teóricas. Na Francia da posguerra, a partir sobre todo dos anos sesenta e setenta, o movemento bretón viuse de novo un tanto escurecido pola maior visibilidade política e apoio social, en termos relativos, do movemento nacionalista corso, acompañado de expresións de violencia. Con todo, a hexemonía teórica do nacionalismo bretón habería perdurar até a irrupción do intelectual occitanista Robert Lafont nos finais da década de 1950, canda o seu modelo do «colonialismo interior», que acadou unha notábel repercusión noutras «periferias étnicas» da Europa occidental, dende Galicia até Sardeña ${ }^{16}$.

Pola contra, e como é ben coñecido nestas latitudes — polo que evitamos entrar nunha descrición polo miúdo—, o galeguismo político e cultural, malia nacer case ao mesmo tempo que o movemento catalanista, non experimentou o forte crecemento que o catalanismo e, en menor medida, o nacionalismo vasco coñeceron a partir do «desastre» colonial de 1898. O galeguismo político, feble organizativamente e esgazado entre unha tendencia liberal e mais outra conservadora-tradicionalista, non deu o salto ao nacionalismo pleno —isto é, á afirmación de Galicia como colectivo titular da soberanía, aínda que sempre cun horizonte federalista e iberista — no 1916-18, coa fundación e primeiros pasos das Irmandades da Fala. Así ocorreu, de feito, noutros movementos da Europa occidental, como o galés, o frisón e o corso, e só uns anos máis tarde do que o fixera o movemento bretón no 1911. No ámbito español, o galeguismo político —non así o cultural— sempre foi un tanto a remolque, con diferentes ritmos, dos nacionalismos catalán, primeiro, e do nacionalismo vasco despois. Cataluña, en efecto, converteuse no máximo referente de emulación política e cultural para o galeguismo de anteguerra e seguiría a selo até a transición á democracia da década de 1970. Iso tivo unha consecuencia paradoxal. O galeguismo foi, deste xeito, un movemento nacionalista que, inicialmente

16 Cf. Xosé M. Núñez Seixas (2020): «Tiers-mondisme, anticolonialisme et ethnonationalisme en Europe occidentale (1955-1975)", en Tudi Kernalegenn / Joel Belliveau / Jean-Olivier Roy (eds.), La vague nationale des années 1960 : une comparaison internationale, Ottawa, Presses de l'Université d'Ottawa, 35-54. 
na década de 1930, grazas á fundación dun partido unificado, o Partido Galeguista (PG), e até o estoupido da Guerra Civil española, e máis tarde na década de 1990, experimentou un crecemento e cobrou un protagonismo social considerábeis, polo menos analizados en perspectiva comparada con outros movementos nacionalistas minoritarios da Europa occidental na época de entre as guerras e de posguerra. Con todo, e malia erixirse en varios períodos nun actor político significativo da escena política galega (anos trinta, Transición, Galicia autonómica), non así na española, xamais no decurso da súa historia chegou a ser hexemónico na sociedade galega. A súa máxima cota situouse arredor do $20 \%$ ou $25 \%$ dos votos na segunda metade da década de $1990^{17}$.

Porén, ao mesmo tempo, o galeguismo político, cuxo paralelo máis acaído en Europa é probabelmente o movemento nacionalista galés, sempre se viu escurecido, no tocante á súa proxección e visibilidade exteriores, polo meirande pulo do catalanismo e do nacionalismo vasco, mais tamén o foi polo feito de escribir nunha lingua minoritaria (o galego), mentres que os textos bretonnants usaron e usan o francés, e por tentar inserirse nun ámbito igual de periférico ou máis no contexto europeo, como é o espazo da lusofonía. Certamente, a compaña no mesmo Estado doutros movementos nacionalistas máis avanzados exerceu, así mesmo, un efecto positivo, pois foron sempre os «irmáns maiores» cataláns e vascos os que forzaron en 1931-36 e dende 1975 a xeneralización da descentralización da estrutura do Estado a outros territorios de España. De esguello, ás veces como efecto colateral, iso tamén beneficiou a Galicia, que hoxe talvez non desfrutaría do grao de autogoberno que ten sen o papel de vangarda desempeñado nese senso polo catalanismo e o nacionalismo vasco, que tanto no 1931-32 como no 1976-80 aquelaron a estrada da descentralización da que tamén se beneficiaría a fisterra atlántica ${ }^{18}$.

\section{II}

Hai, xa que logo, algunhas semellanzas xenéricas entre as situacións históricas e identitarias de Galicia e a Bretaña. Mais tamén existen algunhas diferenzas especificas. Cales son estas?

\footnotetext{
17 Vid. Justo Beramendi (2007): De provincia a nación: historia do galeguismo politico, Vigo, Xerais; Justo G. Beramendi / Xosé M. Núnez Seixas (21996): O nacionalismo galego, Vigo, A Nosa Terra.

${ }^{18}$ Cf. Luis Moreno (2008): La federalización de España: poder politico y territorio, Madrid, Siglo XXI.
} 
En primeiro lugar, a extrema ambivalencia da etnicidade. Malia o abandono progresivo da lingua galega pola burguesía e boa parte das camadas medias urbanas dende a Idade Moderna, e (a diferenza da Bretaña) a escasa empatía da Igrexa católica cara ao galego — nin sequera como instrumento para frear a penetración da secularización e da modernización liberal—, é indubidábel que o idioma propio revestiu, dende comezos do século Xx, e posúe actualmente unha relevancia e puxanza en Galicia moito maiores que as que teñen na Bretaña. Neste caso, a decadencia das linguas propias (o bretón, lingua celta, e mais o galó, lingua britorromance emparentada cos dialectos normando e pictevino e falada en tempos na parte oriental da Bretaña) foi imparábel dende os inicios do século xx, até convertérense en practicamente residuais na actualidade ${ }^{19}$. Evidenciábase nese aspecto, de entrada, a diferente axencia e eficacia nacionalizadora dos Estados español e francés; mais tamén o impacto das dúas guerras mundiais, que contribuíron a estender na sociedade bretoa, coma na francesa toda, a conciencia nacional frances $\mathrm{a}^{20}$.

Con todo, o feito de o galego ser un idioma romance, ao contrario do bretón, lingua celta pertencente a unha familia diferente do francés, favoreceu tamén o bilingüismo e os transvasamentos idiomáticos. Así e todo, o galeguismo dende 1916 é un movemento maioritariamente monolingüe en galego no que atinxe aos seus medios de expresión e mais á súa cultura política; ergueu dende aquela a bandeira da reivindicación do idioma e segue a aspirar a unha sociedade normalizada en galego, na que este idioma teña como mínimo unha posición de igualdade co castelán. Iso reflectiuse de maneira específica na cultura política do galeguismo, na que o idioma é un elemento substancial e irrenunciábel. En troques, o movemento bretón defende a preservación do bretón e do gallo, mais xa dende o período de entre as dúas guerras levou a cabo máis ben un uso sobre todo simbólico do idioma, así como da identidade «céltiga» transnacional a el

19 Cf. Henrique Monteagudo (22017): Historia social da lingua galega: idioma, sociedade e cultura a través do tempo, Vigo, Galaxia; M. Hosby / D. Vigers (eds.) (2013): Breton: The Postvernacular Challenge, Berlin, De Gruyter Mouton; Fañch Broudic (1996): La pratique du breton de l'Ancien Régime à nos jours, Rennes, Presses Universitaires de Rennes.

20 Para un ensaio de visión sintética, $c f$. Xosé M. Núñez Seixas / Fernando Molina (2018): «Regionalism in Southwestern Europe: France, Spain, Italy and Portugal», en Xosé M. Núñez Seixas / Eric Storm (eds.), Regionalism and Modern Europe: Identity Construction and Movements from 1890 to the Present Day, London, Bloomsbury, 233-249. 
asociada. Amósano, por exemplo, algúns textos reveladores, como as memorias da historiadora bretoa e filla de activistas bretonnants Mona Ozouf ${ }^{21}$.

Pola contra, outros trazos diacríticos da identidade colectiva si presentan, no caso bretón, unha forza igual ou maior que no caso galego, dende a música «celta» até o amor por certos símbolos, que mostran o orgullo das orixes «céltigas» — unha impostura no caso galego, con máis visos de verosimilitude no caso bretón, malia o celtismo ser unha invención cultural do XIX e a definición de que é ser «celta» resultar moi problemática- De aí o cultivo, a partir do segundo terzo do século XIX, da literatura de tradición oral, dende o Barzaz Breiz de Hersart de la Villemarqué á posterior adopción na Bretaña dos festivais druídicos (Goursez Vreizh), seguindo o exemplo dos eisteddfodau galeses como forma de sociabilidade burguesa, o cultivo do folclore e mais o seu anovamento posterior etcétera ${ }^{22}$.

En segundo lugar, o papel diferencial desempeñado polas migracións, as diásporas e mais os «nacionalismos de longa distancia». En ambos os dous países a emigración ten maior influxo que a inmigración na configuración da súa respectiva identidade colectiva. No caso galego, o peso da emigración transoceánica é moito meirande que no bretón, no cal as migracións se dirixiron sobre todo a París e outros lugares de Francia. Os grupos bretonnants aquí radicados, ben como os estabelecidos na costa leste dos Estados Unidos, tiveron unha certa relevancia na historia do movemento bretón, así como no artellamento da súa cultura e dalgunhas das súas manifestacións máis coñecidas — por exemplo, os grupos musicais "celtas»" ${ }^{23}$. Porén, o seu papel non é nin de lonxe comparábel ao peso da diáspora americana (e, en menor medida, europea) no caso galego, no cal boa parte dos estímulos e apoios para as endeitas de emancipación política e cultural viñeron das comunidades de emigrantes. Aquelas iniciativas, tanto políticas como

${ }^{21}$ Mona Ozouf (2009): Composition française : retour sur une enfance bretonne, Paris, Gallimard.

22 Cf. Bernard Tanguy (1977): Aux origines du nationalisme breton : le renouveau des études bretonnes au XIX siècle, Paris, Union générale d'éditions; Nelly Blanchard (2006): Barzaz-Breiz : une fiction pour s'inventer, Rennes, Presses Universitaires de Rennes; Philippe Le Stum (1998): Le néo-druidisme en Bretagne : origine, naissance et développement (1890-1914), Rennes, Éditions Ouest-France; Erwan Chartier (2010): La construction de l'interceltisme en Bretagne, des origines à nos jours : mise en perspective historique et idéologique, tese de doutoramento, Rennes, Université Rennes 2.

${ }^{23}$ Cf. Leslie Page Moch (2012): The Pariahs of Yesterday: Breton Migrants in Paris, Durham, NC, Duke University Press, ben como Aurélie Épron / Ronan Le Coadic (eds.) (2017): Bretagne, migrations et identité, Rennes, Presses Universitaires de Rennes. 
culturais, non naceron fóra, senón dentro, mais foron elaboradas e amplificadas adoito por migrantes ou persoas con experiencia emigrante ${ }^{24}$.

En terceiro lugar, a existencia dunha relación complexa entre a conciencia nacional, rexional e local en ambos os dous casos, Galicia e a Bretaña. No caso galego, pódese afirmar que existe dende mediados do XIX unha forte identidade supralocal de carácter rexional ou mesoterritorial, cuxos trazos diacríticos son a etnicidade diferencial — fálese o idioma propio ou non, practíquese a diglosia lingüística ou non-, unha esluída conciencia dun pasado histórico compartido e mesmo algúns atributos psicosociais, como o Volksgeist ou «espírito popular», hoxe aínda rastrexábel na idealización e tipificación dalgúns trazos de carácter supostamente galaico, tales que a ironía campesiña ou retranca, o sentido do humor e a saudade ou morriña. A iso uniríase a vulgarización doutros trazos, como o «celtismo» popular ${ }^{25}$. Esa forte identidade colectiva, porén, mantense nun nivel maiormente prepolítico ou, se se quere, prenacional, e sitúase de xeito maioritario nun estadio de conciencia rexional. Para a maioría social, o forte acento na galeguidade xamais se viu en contradición coa «patria grande», con España toda. Pola contra, enténdese que ser galego é unha forma peculiar e mesmo idiosincrática de ser español. Un sentimento subdividido pola súa vez en localismos e parroquialismos varios, e no que tamén as identidades máis ou menos artificiais de ámbito provincial, fomentadas dende as institucións creadas ad hoc dende 1833-34 (deputacións provinciais), desempeñan un certo papel. A «ourensanía» de que fai bandeira identitaria a Deputación de Ourense dende 2011 podería ser un caso, ben como o "coruñesismo» de décadas anteriores e mais o "viguismo» do actual alcalde Abel Caballero, superposto á tradicional dialéctica entre Vigo e Pontevedra, que se retrotrae aos comezos do século Xx, ademais das identidades colectivas de carácter fronteirizo, como a baixomiñota ou a valdeorresa ${ }^{26}$.

\footnotetext{
24 Xosé M. Núñez Seixas (1992): O galeguismo en América, 1879-1936, Sada, Ediciós do Castro; íd. (2016): O soño da Galiza ideal: estudos sobre exilados e emigrantes galegos, Vigo, Galaxia.

${ }^{25}$ Cf. Manuel Mandianes Castro (2003): O río do esquecemento: identidade antropolóxica de Galicia, Vigo, Xerais, ben como a interesante achega de Santiago Lamas Crego (2004): Galicia borrosa, Sada, Ediciós do Castro. Dende o punto de vista dos estudos literarios, cf. Helena Miguélez-Carballeira (2016): «Sentimentality as Consensus: Imagining Galicia in the Democratic Period», en Luisa Elena Delgado / Pura Fernández / Jo Labanyi (eds.), Engaging the Emotions in Spanish Culture and History, Nashville, Vanderbilt University Press, 210-224.

${ }^{26}$ Ramón Villares (2017): Identidades e afectos patrios, Vigo, Galaxia.
} 
Existe neste aspecto unha substancial diferenza co caso da Bretaña, cuxo territorio histórico foi dividido de xeito artificial en varios departamentos dende a Revolución Francesa. Na Bretaña non sempre hai consenso sobre cales son os seus límites, non recoñecidos no ámbito administrativo; na cidade de Nantes, a identidade local non sempre acha acomodo dentro do conxunto bretón, e nas áreas falantes de galó son moitos os que prefiren identificarse con departamentos franceses fronteirizos. No caso de Galicia, eses lindes territoriais sempre foron ben nidios, tanto cara ao sur (raia portuguesa) como cara ao leste (límites con Castela e León e Asturias). De feito, a relevancia das bisbarras galegófonas do Bierzo leonés, de Zamora e da Asturias occidental, o "galego estremeiro», é no caso galego moi inferior ao papel político e simbólico desempeñado polos territorios «irredentos» noutros casos ibéricos, como o País Vasco, e na Europa centrooriental ${ }^{27}$. Pola contra, a relevancia outorgada a Portugal como irmán maior e referente de «reintegración» ou de inserción pannacional no seo dunha lusofonía da que o galeguismo sempre se sentiu parte integrante, aínda que con matices, posúe algúns paralelismos co sentimento pancelta pregoado por varias tendencias do nacionalismo bretón, nomeadamente cara a Irlanda e o País de Gales.

A forte identidade galega caracterízase, en todo caso, pola súa natureza prenacional. Tradúcese no que se podería denominar hipertrofia de galeguidade de país, pero non acompañada de conciencia nacional. Non necesariamente se espreme, ou só se fai de xeito minoritario —aínda que non irrelevante: arredor do $15 \%$ ou $20 \%$ da poboación-, en forma de conciencia nacional exclusiva ou diferencial. E nese aspecto pódese rastrexar un certo paralelismo coa Bretaña. Porén, no que xa existe unha máis que notábel diferenza é na relevancia sociopolítica e electoral do movemento etnonacionalista, que é moito máis autónomo e forte no caso galego que no bretón, no cal a Union démocratique bretonne (UDB, fundada no 1964) e outras organizacións se moven en niveis de voto e influencia social e política ben modestos. Adoito, eses partidos especificamente nacionalistas víronse forzados a integrar coalicións multicor con outros actores políticos alternativos,

27 Cf. Álvaro Xosé López Mira (1998): A Galicia irredenta, Vigo, Xerais; Xosé Antonio Fernández de Rota e Monter (dir.) (1990): Lindeiros da galeguidade, Santiago de Compostela, Consello da Cultura Galega; íd. / Xosé Antón Fidalgo Santamariña / Xosé Manuel González Reboredo (coords.) (1993): Lindeiros da galeguidade II, Santiago de Compostela, Consello da Cultura Galega. 
dende o Partido Socialista francés até a esquerda poscomunista, pasando polo forte movemento ecoloxista bretón, cuxas reivindicacións se «territorializaron»e se identificaron de maneira progresiva coa defensa da identidade bretoa dende a década de $1980^{28}$.

Iso lévanos a unha cuarta dimensión: o diferente papel do nacionalismo político (e cultural) nas dúas fisterras europeas. Aínda que algún autores os teñan situado case á par, presentándoos como exemplo de movementos nacionalistas que teñen lugar en circunstancias desfavorábeis ${ }^{29}$, é un feito certo que, en comparanza co caso da Bretaña, en Galicia o nacionalismo político experimentou un moito meirande desenvolvemento e influxo social. Se o movemento bretonnant ou emsav nacera politicamente con máis forza que o galeguismo na primeira década do século Xx, a relación inverteuse de maneira clara ao longo da década de 1920. No aspecto social e organizativo, o PG de 1932-36, no camiño de converterse nun partido de masas, estaba a anos luz do Parti national breton e mais do resto de organizacións nacionalistas do segundo emsav, que se amosaban incapaces de ultrapasar o seu estadio de ananismo social e hiperactivismo cultural e ideolóxico. Mesmo cando o galeguismo se achou na clandestinidade durante a época franquista, ao mozo Xosé Manuel Beiras, durante a súa estadía en terras francesas, os círculos bretonnants que coñeceu no 1957-58 na Universidade de Rennes causáranlle pobre impresión, por achárense nun estadio ideolóxico "pouco desenvolvido".

Pasados os anos da fervedoira terceiromundista e revolucionaria da década dos sesenta, así aconteceu a partir de 1975-77, cando o nacionalismo galego de selo populista e marxista-leninista saíu á superficie e participou en procesos electorais. As súas opcións, sen dúbida, víronse, no caso galego, favorecidas por unha estru-

${ }^{28}$ Cf. Tudi Kernalegenn (2011): «Une approche cognitive du régionalisme : identités régionales, territoires, mouvements sociaux en Bretagne, Écosse et Galice dans les années 1970», tese de doutoramento, Rennes, Université Rennes 2; Tudi Kernalegenn et al. (eds.) (2007): Bretagne plurielle : culture, territoire et politique, Rennes, Presses Universitaires de Rennes; Tudi Kernalegenn (2014): Histoire de l'écologie en Bretagne, Rennes, Goater; Yann Fournis (2006): Les régionalismes en Bretagne : la région et l'État, Bruxelles, Peter Lang; Tudi Kernalegenn / Romain Pasquier (dirs.) (2014): L'Union démocratique bretonne : un parti autonomiste dans un État unitaire, Rennes, Presse Universitaires de Rennes; Ronan Le Coadic (2002): Bretagne : le fruit défendu?, Rennes, Presses Universitaires de Rennes.

${ }_{29}$ Miroslav Hroch (2005): Das Europa der Nationen: die moderne Nationsbildung im europäischen Vergleich, Göttingen, Vandenhoeck \& Ruprecht. 
tura de oportunidade política máis aberta do que era o sistema político francés. $\mathrm{Na}$ nova democracia española imperaría un sistema electoral proporcional corrixido, con circunscricións provinciais, e abríronse amplos ámbitos mesoterritoriais de competición electoral, o que operou a prol da existencia de partidos de ámbito non estatal. Porén, no caso de Francia a falla de descentralización política e de creación de ámbitos rexionais de competición político-institucional, sumada á presenza de distritos electorais maioritarios a dúas voltas, supuña un atranco considerábel para a consolidación de forzas políticas de ámbito subestatal que puidesen presentar unha alternativa aos grandes partidos da dereita e esquerda francesas.

Ambos os dous movementos políticos, o nacionalismo galego e mais o nacionalismo bretón, caracterízanse ademais, dende mediados dos anos sesenta, por un nesgo político moi envorcado cara á esquerda e mesmo a extrema esquerda, sen contrapeso nunha oferta de orientación conservadora ou liberal, agás grupos minoritarios. Este espazo político foi ocupado adoito por grupos políticos de obediencia estatal tanto no centroesquerda como no centrodereita, que foron quen de captar militantes e personalidades sobranceiras do galeguismo cultural que preservaran durante a ditadura franquista o legado do nacionalismo de antes da guerra, e que fixeron bandeira, pola súa vez, dun tépedo rexionalismo cultural ${ }^{30}$. En ambos os dous casos bótase en falla a existencia dun núcleo forte de clases medias urbanas que se identifiquen cos postulados nacionalistas subestatais. $\mathrm{O}$ que, con todas as cautelas, puidermos chamar unha «burguesía nacional».

Con todo, o crecemento e a extensión social da identidade especificamente nacional galega dende a morte de Franco foron relativamente modestos, e xamais se converteron en hexemónicos. Mesmo no período de maior crecemento dos referentes de identidade nacional exclusivamente galegos — a década de 1990_, a porcentaxe de persoas que declaraban nos inquéritos de opinión seren «só galegas» ou «máis galegas que españolas» sobordaba un $35 \%$ da poboación. Os polos «só español» e «máis español que galego» eran máis febles, mentres que, pola contra, a categoría «tan galego coma español» sempre recollía adhesións maioritarias. Se os referentes de identidade galega (exclusiva ou máis galego que español)

30 Cf., para unha panorámica integrada e actualizada, Emilio Grandío Seoane (ed.) (2015): La Transición en Galicia, dossier da revista Historia del Presente, 25:1, 5-95. 
parecía que se robustecían de xeito considerábel, aínda que non espectacular, despois da posta en marcha do Estatuto de autonomía no 1980-81 e semellaban ter un correlato no crecemento paralelo do apoio social ao nacionalismo político (unificado daquela na súa case totalidade no Bloque Nacionalista Galego, BNG) durante os anos noventa e até 2001, dende entón obsérvase un estancamento e mesmo unha diminución dos polos «só galego» e «máis galego que español». De acudirmos a outro tipo de indicadores, como as preferencias polo modelo de Estado, a conclusión dende a década de 1990 tamén era clara: a maioría da cidadanía galega gostaba do Estado das autonomías como está, unha minoría arela a autodeterminación e arredor dun $20 \%$ ou 25\% se pronunciaría por máis autonomía ou por un Estado federal, calquera que fose a forma concreta que este adoptase. Aí, ademais, abríase outro debate: que entende a maioría da cidadanía por federalismo?

De feito, máis da metade dos que outorgaban o seu sufraxio na década de 1990 ao BNG, na súa época de maior auxe, non compartían boa parte dos puntos da súa táboa de reivindicacións políticas en materia de autogoberno e soberanía, ou en materia de normalización lingüística (evidente no caso do voto urbano ao BNG, mesmo hoxe en cidades como Pontevedra). Con todo, si arelaban que Galicia tivese voz propia no concerto da España autonómica, e que aspirase a un reforzamento dos seus sinais de identidade e da defensa dos seus intereses colectivos. De feito, era este un lema ao que o BNG outorgou especial prioridade durante os seus anos de forte crecemento: ser unha forza «útil» ao servizo dos «intereses galegos» e do seu sistema produtivo, aínda que o discurso de uso interno apelase a reivindicacións e obxectivos etnonacionalistas clásicos, como o idioma e mais a soberanía. E, en efecto, o nacionalismo galego — nomeadamente, o BNG - aumentaba en votos, grazas á unificación do voto galeguista até entón disperso en varias forzas, á incorporación de votantes novos ao censo e mais á captación do voto de novas clases medias que votaran denantes ao Partido Socialista (PSOE) ${ }^{31}$. Porén, o movemento nacionalista non foi quen de artellar ou promover a formación dun tecido mesto na sociedade civil que servise de circio

31 Para unha panorámica, cf. Xosé M. Núñez Seixas (2003): «Zwischen regionaler Selbstwahrnehmung und radikalem Ethnonationalismus: Galicien, 1960-2000», en Philipp Ther / Holm Sundhaussen (eds.), Regionale Bewegungen und Regionalismen in europäischen Zwischenräumen seit der Mitte des 19. Jahrhunderts, Marburg an der Lahn, Verlag Herder-Institut, 161-183. 
apoio á reivindicación nacionalista en calquera circunstancia, independentemente das variacións na esfera político-partidaria e electoral ${ }^{32}$.

Esa debilidade do nacionalismo como movemento multisectorial, alén da dimensión sindical, púñase en evidencia nalgúns apartados sensíbeis. Un deles, talvez o máis significativo, era e é a só relativa forza do movemento social en prol da normalización da lingua, cuxa implantación é menor da que ten o nacionalismo político ou sindical. En Galicia, por exemplo, non hai polo de agora nada comparábel ao movemento de escolas primarias e infantís en bretón (as escolas Diwan, fundadas no 1977 a inspiración das ikastolak vascas ou as calandretas occitanas, que acadaban un número de 48 no 2016), pois fíase en exceso de acadar o poder autonómico e de ser capaz de utilizar as súas pancas para, dende el, transformar a sociedade e os seus sentimentos de pertenza. É, neste senso, significativo que a iniciativa máis semellante ás escolas Diwan, a rede de gardarías en galego Galescolas, fose impulsada polo nacionalismo só cando estivo no poder do 2005 ao 2009, en coalición co PSOE ${ }^{33}$.

É cuestión de debate, e non abordábel nestas páxinas, se o fenómeno anterior é unha causa ou unha consecuencia da debilidade do apoio social a parte dos postulados galeguistas. Isto é, se se tratou dunha sorte de elección racional por parte do nacionalismo militante, motivada polo seu realismo, tamén tinxido de desencanto e de pesimismo perante a suposta pasividade da sociedade galega sobre a que se tenta influír (e que só sería transformábel dende o poder); ou ben se iso foi e aínda é así por outra razón máis fonda, a cultura política imperante no nacionalismo galego de esquerda dende a Transición. Esa cultura política tende a observar con receo todo o que verdadeiramente soe a sociedade civil autónoma.

32 Para unha historia da evolución do BNG até a primeira década do século XXI, vid. X. R. Quintana Garrido (2010): Un longo e tortuoso camiño: adaptación, crise e cambio no Bloque Nacionalista Galego (1982-2008), Vigo, Galaxia. Algúns acenos interesantes para o período posterior en Anxo Lugilde (2014): De Beiras a Podemos: a politica galega nos tempos da troika (2012-2014), s. l., Praza Pública / Meubook, ben como en Xoán Hermida González (2018): Galicia no labirinto da nova política: de Nunca Máis ás Mareas, Vigo, Galaxia.

33 Henrique Monteagudo (2009): As razóns do galego: apelo á cidadanía, Vigo, Galaxia; íd. (ed.) (2012): Linguas, sociedade e politica: un debate multidisciplinar, Santiago de Compostela, Consello da Cultura Galega. Unha perspectiva diferente en Carlos Callón (2017): Galegocalantes e galegofalantes, Vigo, Xerais, ben como en Xosé Ramón Freixeiro Mato (2010): «Les voies d'avenir de la langue galicienne á l'ère de la globalisation", Diacrítica, 54:2, 491-521. 
Unha excepción dentro do panorama do nacionalismo galego como movemento social — como xa sinalamos, moito máis desenvolvido e forte que no caso do movemento bretón, que é máis feble e dependente de alianzas políticas con outros actores, dende esquerda radical até ecoloxistas - é o sindicalismo. Trátase dunha diversificación sectorial xa dirixida polas instancias políticas do nacionalismo nos anos setenta e, por tanto, unha estratexia de diversificación dende enriba do propio movemento, e non tanto unha xeración autónoma dende a base. Con todo, o sindicalismo nacionalista experimentou un notábel éxito a partir da década de 1980 e chegou a copar o espazo alternativo á marxe dos grandes sindicatos estatais españois (UGT e CC. OO.), grazas, en boa medida, ás súas estratexias negociadoras e á súa capacidade de implantación en sectores como o funcionariado, a sanidade, as pequenas empresas e, igualmente, clásicos como os estaleiros navais (en fonda reconversión e devalo dende a década de 1980) e mais a industria da automoción. Deste xeito, a Confederación Intersindical Galega, CIG, que reúne arredor dun $25 \%$ dos delegados sindicais, é na segunda década do século XXI un dos tres sindicatos maioritarios do país. Con todo, cómpre non esquecer que o sindicalismo se distingue por unha dinámica de seu, dependente das relación laborais, e non sempre é automaticamente traducíbel en conciencia nacional diferencial ${ }^{34}$.

O devalo ou estancamento da conciencia especificamente nacional galega dende a primeira década do século XXI podería ser un sinal de que, fronte ao que era unha opinión académica e política xeneralizada xa dúas décadas atrás, a autonomía por si propia non sempre creaba nacionalistas ${ }^{35}$, aínda que si moldeaba ou robustecía a conciencia social da existencia dun marco territorializado de intereses e de percepcións compartidos. Iso traduciríase na consolidación de marcos de intelección que daban prioridade aos «intereses galegos», ás «marcas galegas», á «defensa do territorio» etcétera. Marcos que se asentaron nos medios de comunicación, tanto nos de titularidade pública como en boa parte dos pri-

\footnotetext{
34 Un paralelismo, neste senso, pode ser o caso do sindicalismo nacionalista corso: o Sindicatu di i travagliadori corsi (STC) é dende 2002 a primeira forza sindical da illa; $c f$. Giuseppe Consiglio (2018): "Corsica indipendente: insularità identitaria ai tempi dell'Europa unita», en Andrea Geniola / Isidoro Davide Mortellaro / Daniele Petrosino (eds.), Stati, regioni e nazioni nell'Unione europea, Napoli, Editoriale Scientefica, 247-258.

35 Cf. Ramón Máiz / Antón Losada (2000): «Institutions, Policies and Nation-building: The Galician Case», Regional and Federal Studies, 10:1, 62-91; Julio Cabrera Varela (1996): "Cambio cultural e identidade colectiva en Galicia», Grial, 130, 227-243.
} 
vados, moi dependentes financeiramente do poder autonómico. Callaría así nun amplo sector da poboación a idea de que Galicia era un ámbito político, cultural e socioeconómico de seu: un marco de referencia e de intelección de características e intereses compartidos, certamente sobrevido grazas á xeneralización da autonomía a todos os territorios do Estado español en 1977-80, mais non por iso menos influente.

Escusado é dicir que iso non convertía a Galicia nunha nación, nun suxeito do «dereito a decidir», pero si en marco preferente de adscrición identitaria, aínda que non incompatíbel co español. De baseármonos en varias enquisas realizadas dende a década de 1990 até a primeira década do século XXI, á pregunta de «que é Galicia», arredor dun 20 \% (algo menos hoxe en día) dos cidadáns abordados respondía que era unha nación ou nacionalidade, o que era unha porcentaxe máis ou menos congruente co nivel de voto nacionalista galego en eleccións autonómicas; porén, a maioría opinaba que Galicia era/é unha rexión ou comunidade autónoma. Mais os trazos que eses cidadáns apoñían a «rexión», «nacionalidade» e «nación» eran sumamente variábeis, pois había cidadáns que lle atribuían á «rexión» características histórico-políticas case equiparábeis ás de «nación». Con todo, iso non presupuña que para eles existise contradición ningunha entre ser galego e ser español e, por tanto, non se sentisen parte dunha nación galega non integrábel dentro dun ente, España, tamén revestido de características afectivas ${ }^{36}$.

En quinto lugar, cómpre lembrar unha lección bretoa, de aplicación a Galicia: a definición dos trazos diacríticos da identidade colectiva non sempre é a mesma, nin o ha $\operatorname{ser}^{37}$. Certamente, son moitos os nacionalistas, os galeguistas e mais os activistas pola cultura galega que se laian de estarmos a «quedar sen país». Un motivo de alarma é a progresiva diminución do número de falantes nativos de galego, sobre todo en áreas urbanas e periurbanas, posta de relevo polos sucesivos estudos sociolingüísticos, só parcialmente compensada polos neofalantes e mais pola maior visibilidade do emprego do galego na esfera pública ${ }^{38}$. Únense a iso

36 Ramón Máiz (ed.) (2004): Identidade colectiva e medios de comunicación: La Voz de Galicia, 1977-1996, Santiago de Compostela, Centro Ramón Piñeiro para a Investigación en Humanidades. Vid. tamén Marcelino Agís Villaverde (coord.) (2014): 30 anos de autonomía, Santiago de Compostela, Correo.

37 Ronan Le Coadic (1998): Lidentité bretonne, Rennes, Presses Universitaires de Rennes.

38 Henrique Monteagudo / Xaquín Loredo / Martín Vázquez (2016): Lingua e sociedade en Galicia: a evolución sociolingüistica, 1992-2013, A Coruña, Real Academia Galega. 
o devalo demográfico e a crecente urbanización: Galicia ten imaxe aínda de país rural, mais xa non o é; o rural é cada vez menos agrario ${ }^{39}$. Os refuxios «tradicionais» da etnicidade galega recúan de maneira irremisíbel, e cómpre adaptar aquela aos novos tempos, urbanos e globalizados, tamén mediante unha valorización do carácter transatlántico e transnacional da propia identidade galega ao longo da súa historia recente ${ }^{40}$. Porén, talvez cumpriría no caso galego que os defensores da súa identidade fosen máis pragmáticos niso, «desfiloloxizar» os sentimentos de identidade, incorporar de xeito decidido elementos como a cultura diaspórica e dotar de contidos positivos e modernos (cultivo da innovación, respecto polo medio ambiente etcétera) o propio concepto de identidade galega.

Nese senso, o espello da Bretaña e mais as opción e estratexias dos activistas bretonnants de diferentes cores e tendencias, incluído o seu maior pragmatismo identitario, quizais poden servir de contrapunto para a comparanza e de reflexión. Non todo está perdido, senón que o futuro se acha nas mans dos habitantes desta fisterra atlántica, dos galegos e das galegas. Que Galicia se defina doutra maneira, e, con iso, os elementos que se supón que son característicos da galeguidade, non quere dicir que esa identidade por forza desapareza; sinxelamente, que se transforma, con valencias e implicacións sociopolíticas non sempre previsíbeis.

39 Cf. Manuel Blanco Desar (ed.) (2014): Galicia, un pobo con futuro?: o noso devalo demográfico, Vigo / Santiago de Compostela, Xerais / Museo do Pobo Galego.

40 Cf. Ramón Villares (2019): Galicia: una nación entre dos mundos, Barcelona, Pasado y Presente. 